\title{
Effect of Viscous Dissipation on Natural Convection in a Non-Darcy Po- rous Medium Saturated with Non-Newtonian Fluid of Variable Viscosity
}

\author{
R.R. Kairi ${ }^{1}{ }^{*}$, P.V.S. N. Murthy ${ }^{1}$ and C. O. $\mathrm{Ng}^{2}$ \\ ${ }^{I}$ Department of Mathematics, Indian Institute of Technology Kharagpur- 721 302, India \\ ${ }^{2}$ Department of Mechanical Engineering, The University of Hong Kong, Hong Kong
}

\begin{abstract}
This paper investigates the influence of the effect of viscous dissipation and radiation on natural convection heat transfer from vertical flat plate in a non-Darcy porous media saturated with non-Newtonian fluid of variable viscosity. The wall and the ambient medium are maintained at constant but different levels of temperature. The Ostwald-de Waele power law model is used to characterize the non-Newtonian fluid behavior. The viscosity of the fluid is assumed to follow Reynolds viscosity model. Rosseland approximation is used to describe the radiative heat flux in the energy equation. The governing equations in their non-similar form are solved numerically by local non-similarity method. The effects of variable viscosity, viscous dissipation, radiation and the power-law index parameters on the velocity and temperature profiles as well as on the heat transfer coefficient are analyzed.
\end{abstract}

Keywords: Natural convection, non-darcy porous media, viscosity, non-newtonian, thermal radiation, viscous dissipation.

\section{INTRODUCTION}

The study of convection heat transfer from a vertical flat plate embedded in a porous medium has attracted many investigators due to its wide range of applications in geophysics and energy related problems such as thermal insulation, enhanced recovery of petroleum resource, geophysical flows, polymer processing in packed beds and sensible heat storage bed. In particular, a number of industrially important fluids including fossil fuels exhibit non-Newtonian fluid behavior. Non-Newtonian power law fluids are so widespread in industrial processes and in the environment that it would be no exaggeration to affirm that Newtonian shear flows are the exception rather than the rule. Shenoy [1] presented many interesting applications of non-Newtonian power law fluids with yield stress on convective heat transport in fluid saturated porous media considering geothermal and oil reservoir engineering applications. Natural convection of a nonNewtonian fluid about a vertical wall and that around horizontal cylinder and sphere in a porous medium was presented by Chen and Chen [2,3]. Nakayama and Koyama [4] analyzed the more general case of free convection over a non-isothermal body of arbitrary shape embedded in a porous medium. Mehta and Rao [5, 6] analyzed the buoyancy induced flow of non-Newtonian fluids over a non-isothermal horizontal plate and a vertical plate with non-uniform heat flux embedded in a porous medium using a similarity technique. Non-Darcy natural, forced and mixed convection heat transfer in non-Newtonian power-law fluid saturated porous media was studied by Shenoy [7].

\footnotetext{
*Address correspondence to this author at the Department of Mathematics, Indian Institute of Technology Kharagpur- 721 302, India; Tel: 91-3222283646; Fax: 91-3222-282700; E-mail: rishirajkairi@gmail.com
}

Viscous dissipation which, appears as a source term in the fluid flow generates appreciable temperature, gives the rate at which mechanical energy is converted into heat in a viscous fluid per unit volume. This effect is of particular significant in natural convection in various devices that are subjected to large variation of gravitational force or that operate at high rotational speeds, pointed by Gebhart [8] in his study of viscous dissipation on natural convection in fluids. Similarity solution for the same problem with exponential variation of wall temperature was obtained by Gebhart and Mollendor [9]. A comment was made by Fand and Brucker [10] that the effect of viscous dissipation might be significant in the case of natural convection in porous medium in connection with their experimental correlation for the heat transfer in external flows. The validity of the comment was tested for the Darcy model by Fand et al. [11], both experimentally and analytically while estimating the heat transfer coefficient from a horizontal cylinder embedded in a porous medium. Their mathematical analysis is confined to studying the dissipation effect using a steady, 1-D energy equation, on the basis of the equation form analogy given by Bejan [12] for the inclusion of viscous dissipation effects. Nakayama and Pop [13] considered the effect of viscous dissipation on the Darcian free convection over a non-isothermal body of arbitrary shape embedded in porous media. The influence of viscous dissipation can be seen from the analogy given by Tucker and Dessenberger [14] to model the heat transfer and fluid flow through the porous media in order to study the Resin Transfer Molding (R. T. M) for producing fiber reinforced polymeric parts in final shape. Later, Murthy and Singh [15] studied viscous dissipation on non-Darcy natural convection regime in porous media saturated with Newtonian fluid. They concluded that a significant decrease in heat transfer is observed with inclusion of viscous dissipation effect. Many non-Newtonian liquids are highly viscous such 
that the irreversible work due to viscous dissipation can, in some instances, become quite important which motivated researcher to study the viscous dissipation phenomena in non-Newtonian fluid saturated porous media. El-Amin [16] examined combined effect of MHD and viscous dissipation on power law fluids on a plate embedded in the porous media.

Depending on the surface properties and solid geometry, radiative transport is often comparable with that of the convective heat transfer in many practical applications. Radiation and free convection flow through a porous medium using Rosseland approximation for the radiative heat flux analyzed by Raptis [17]. Chamkha [18] studied solar radiation assisted free convection in the boundary layer adjacent to a vertical flat plate in a uniform porous medium with a more general Darcy-Forchheimer-Brinkman flow model. Murthy et al. [19] examined the combined radiation and mixed convection from permeable vertical wall in a non-Darcy porous media. Whereas, the thermal radiation phenomena of nonNewtonian fluids over a horizontal plate with variable surface temperature in porous medium was investigated by Mohammadein and El-Amin [20].

A lot of heat convection studies in porous media have been reported with considering constant physical properties of the ambient fluids. However, it is well known that the viscosity of liquid changes evidently with the temperature and this influences the variation of velocity through the flow. Therefore, when we applied to practical heat transfer problems with the large temperature difference between the surface and the fluid, the considering constant viscosity a considerable errors could occurs. Lai and Kulacki [21] consider the variable viscosity effect for a mixed convection flow along a vertical embedded in a porous medium. A theoretical study of temperature dependent viscosity for the forced convection flow thorough the semi-infinite porous medium bounded by an isothermal plate presented by Ling and Dybbs [22] with considering viscosity as inverse function of temperature. Later, Postelnicu et al. [23] extended their work by considering internal heat generation in the medium. The problem of variable viscosity on non-Darcy free or mixed convection flow on a vertical surface in a non-Newtonian fluid saturated porous medium examined by Jayanthi and Kumari [24]. Elbashbeshy [25] numerically investigates the MHD free convection flow variable viscosity and thermal diffusivity along a vertical plate. Flow of a generalized second grade non-Newtonian fluid with viscosity varying exponentially with temperature is studied by Massoudi and Phuoc [26].

Even in the absence of the external applied heat the frictional dissipation or viscous dissipation can cause significant temperature changes with in the fluid which leads the fluid viscosity to vary. The thermal radiation can play a significant role in the over all surface heat transfer in situation where temperature with in the fluid increases with the frictional dissipation. Therefore, the aim of the present investigation is to illustrate combined effect of viscous dissipation and radiation on natural convection in non-Darcy porous medium saturated with non-Newtonian fluid of variable viscosity. In particular we model the viscosity variation by Reynolds law $[26,27]$, which assumes the viscosity decreases exponential with temperature. The governing equations are non- dimensionalized into non-similar form and then solved numerically by local non-similarity method.

\section{MATHEMATICAL FORMULTION}

Consider the steady, laminar, two-dimensional natural convection boundary layer flow over a semi-infinite vertical flat embedded in a saturated porous medium as shown in Fig. (1). The fluid is considered to be gray, absorbingemitting radiation but non-scattering medium, and the Rosseland approximation is used to describe the radiative heat flux in the energy equation. The $x$-coordinate is taken along the plate and $y$-coordinate is measured normal to the plate, while the origin of the reference system is taken at the leading edge of the plate. The porous medium is assumed to be transparent and in thermal equilibrium with the fluid. The wall and ambient media temperature, respectively, are $T_{w}$ and $T_{\infty}$, where $T_{w}>T_{\infty}$ (heated plate). The fluid flow is moderate and the permeability of the medium is assumed to be low so that the Forchheimer flow model is applicable and the boundary-drag effect is neglected. The flow is steady, laminar and two dimensional. With the usual boundary layer and linear Boussinesq approximations, the governing equations, namely the equation of continuity, the non-Darcy flow model (i.e. the model given by Shenoy [7]) and the energy equation for the isotropic and homogeneous porous medium may be written as:

$$
\begin{aligned}
& \frac{\partial u}{\partial x}+\frac{\partial v}{\partial y}=0 \\
& \frac{\partial u^{n}}{\partial y}+\frac{\partial}{\partial y}\left(\rho_{\infty} \frac{b K^{*}}{\mu} u^{2}\right)=\frac{\partial}{\partial y}\left(\frac{\rho_{\infty} g K^{*} \beta_{T}}{\mu}\left(T-T_{\infty}\right)\right) \\
& u \frac{\partial T}{\partial x}+v \frac{\partial T}{\partial y}=\alpha \frac{\partial^{2} T}{\partial y^{2}}+\frac{\mu}{\rho_{\infty} K_{p}^{*}} u \\
& \left(u^{n}+\rho_{\infty} \frac{b K^{*}}{\mu} u^{2}\right)-\frac{1}{\rho_{\infty} c_{p}} \frac{\partial q_{y}^{r}}{\partial y}
\end{aligned}
$$

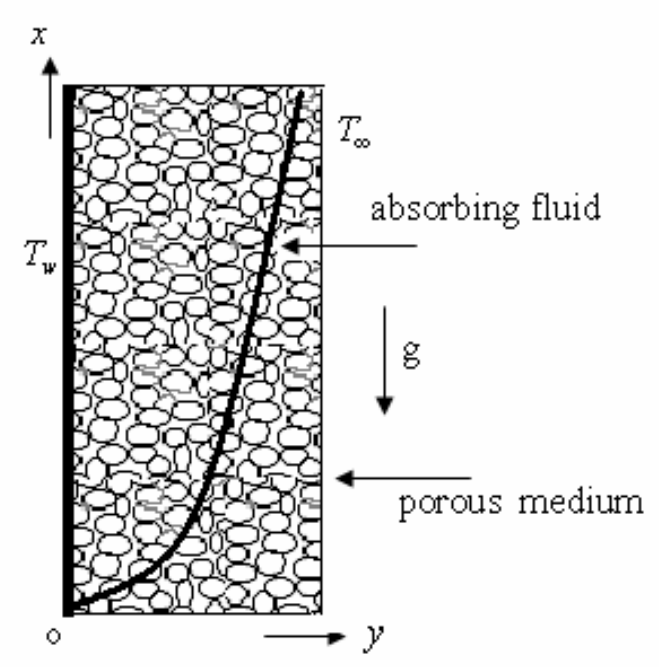

Fig. (1). Physical Model and coordinate system. 
and the boundary conditions are

$y=0: v=0, T=T_{w}$

$y \rightarrow \infty: u \rightarrow 0, T \rightarrow T_{\infty}$

In the above equations, $u$ and $v$ are the average velocity components along the $x$ and $y$ directions, respectively, and $n$ is the power law index ( $n<1, n=1$ and $n>1$, respectively, Pseudoplastics, Newtonian and Dilatant fluids). $T$ is the temperature, $\rho_{\infty}$ is the reference density, $g$ is the acceleration due to gravity, $\alpha$ is the constant thermal diffusivity, $\beta_{T}$ is the coefficient of thermal expansion and $c_{p}$ is the specific heat at constant pressure. Also, $b$ is the empirical constant associated with the Forchheimer porous inertia term and $\mu$ is the consistency index of power law fluid. Following Christopher and Middleman [28] and Dharmadhikari and Kale [29], the modified permeability of the flow $K^{*}$ of the nonNewtonian power law fluid is defined as

$K^{*}=\frac{1}{2 c_{t}}\left(\frac{n \phi}{3 n+1}\right)^{n}\left(\frac{50 K}{3 \phi}\right)^{\frac{n+1}{2}} \phi$ is the porosity of medium

where $K=\frac{\phi^{3} d^{2}}{150(1-\phi)^{2}}$ and

$c_{t}=\left\{\begin{array}{l}\frac{25}{12} \quad \text { Christopher and Middleman [28] } \\ \frac{2}{3}\left(\frac{8 n}{9 n+3}\right)^{n}\left(\frac{10 n-3}{6 n+1}\right)\left(\frac{75}{16}\right)^{3(10 n-3) /(10 n+11)} \quad \text { Dharmadhikariand Kale [29] }\end{array}\right.$

for $n=1, c_{t}=\frac{25}{12}$

The radiative heat flux term $q_{y}^{r}$ is written using Rosseland approximation (Raptis [17], Murthy et al. [19]) as

$q_{y}^{r}=-\frac{4 \sigma}{3 k^{*}} \frac{\partial T^{4}}{\partial y}$

where $\sigma$ and $k^{*}$ are the Stefan-Boltzman constant and the mean absorption coefficient, respectively.

The continuity equation is automatically satisfied by defining a stream function $\psi(x, y)$ such that $u=\frac{\partial \psi}{\partial y}$ and $v=-\frac{\partial \psi}{\partial x}$. We introduce the following similarity transformation:

$\eta=\frac{y}{x} R a_{x}^{1 / 2}, \psi(\varepsilon, \eta)=\alpha R a_{x}^{1 / 2} f(\varepsilon, \eta)$ and $\theta(\varepsilon, \eta)=\frac{T-T_{\infty}}{T_{w}-T_{\infty}}$

where $R a_{x}=\frac{x}{\alpha}\left[\frac{\rho_{\infty} K^{*} g \beta_{T}\left(T_{w}-T_{\infty}\right)}{\mu_{\infty}}\right]^{1 / n}$

The fluid viscosity $\mu(\theta)$ is assumed to obey Reynolds viscosity model $([25,26])$ $\mu(\theta)=\mu_{\infty} e^{-\gamma \theta}$

where $\gamma$ is the non-dimensional viscosity parameter depending on the nature of the fluid and $\mu$ is the ambient viscosity of the fluid. This model can be applicable in many processes where pre-heating of the fuel is used as a means to enhanced heat transfer effect. In addition, for many fluids such as lubricants, polymers, and coal slurries viscous dissipation is substantial, an appropriate constitutive relation where viscosity is a function of temperature should be used.

The above transformation reduces the system of partial differential equations into the following system of nonlinear ordinary differential equations:

$$
\begin{aligned}
& \left(n f^{\prime n-1}+2 G r^{*} e^{\gamma \theta} f^{\prime}\right) f^{\prime \prime}+\gamma G r^{*} e^{\gamma \theta} \theta^{\prime} f^{\prime^{2}}=e^{\gamma \theta} \theta^{\prime}(1+\gamma \theta) \\
& \theta^{\prime \prime}+\frac{1}{2} f \theta^{\prime}+\varepsilon e^{-\gamma \theta} f^{\prime}\left(f^{\prime}{ }^{n}+G r^{*} e^{\gamma \theta} f^{\prime 2}\right)+\frac{4}{3} R \\
& \left(\left(\left(C_{T}+\theta\right)^{3} \theta^{\prime}\right)^{\prime}\right)=\varepsilon\left(f^{\prime} \frac{\partial \theta}{\partial \varepsilon}-\theta^{\prime} \frac{\partial f}{\partial \varepsilon}\right)
\end{aligned}
$$

and the transformed boundary conditions are

$$
\begin{aligned}
& f(\varepsilon, \eta)+2 \varepsilon \frac{\partial f(\varepsilon, \eta)}{\partial \varepsilon}=0, \theta(\varepsilon, \eta)=1 \text { at } \eta=0 \\
& f^{\prime}(\varepsilon, \eta) \rightarrow 0, \theta(\varepsilon, \eta) \rightarrow 0 \text { as } \eta \rightarrow \infty
\end{aligned}
$$

In the above equations $R=4 \sigma\left(T_{w}-T_{\infty}\right)^{3} / k k^{*}$ is the radiation parameter, $C_{T}=T_{\infty} /\left(T_{w}-T_{\infty}\right)$ is the temperature ratio, $C_{T}$ assumes very small values by its definitions as $\left(T_{w}-T_{\infty}\right)$ is very large compared to $T_{\infty}$. The Grashof number $G r^{*}=b\left(\frac{K^{* 2} \rho_{\infty}{ }^{2}\left[g \beta\left(T_{w}-T_{\infty}\right)\right]^{2-n}}{\mu_{\infty}{ }^{2}}\right)^{1 / n}$ is defined based on permeability for power law fluid. In the present study, this parameter is assigned the value 0.1 . The viscous dissipation parameter is given by $\varepsilon=g \beta_{T} x / c_{p}$ (known as the Gebhart number $G e_{x}$ in earlier studies)

Now, integrating Equation (6) one time and taking into the boundary conditions (9) we obtained:

$f^{\prime^{n}}+G r^{*} e^{\gamma \theta} f^{\prime 2}=\theta e^{\gamma \theta}$

Substituting equation (10) in the equations (6) and (7), we further obtain:

$\left(n f^{\prime^{n-1}}+2 G r^{*} e^{\gamma \theta} f^{\prime}\right) f^{\prime \prime}=e^{\gamma \theta} \theta^{\prime}+\gamma \theta^{\prime} f^{\prime^{n}}$

$\theta^{\prime \prime}+\frac{1}{2} f \theta^{\prime}+\varepsilon f^{\prime} \theta+\frac{4}{3} R\left(\left(\left(C_{T}+\theta\right)^{3} \theta^{\prime}\right)^{\prime}\right)=\varepsilon\left(f^{\prime} \frac{\partial \theta}{\partial \varepsilon}-\theta^{\prime} \frac{\partial f}{\partial \varepsilon}\right)$

The non-dimensional heat transfer coefficient or Nusselt number is defined as

$$
N u_{x} / R a_{x}^{1 / 2}=-\theta^{\prime}(\varepsilon, 0)\left[1+\frac{4}{3} R\left(C_{T}+\theta(\varepsilon, 0)\right)^{3}\right]
$$




\section{NUMERICAL METHOD}

We now obtain approximate solutions to the equations (11-12) with the boundary conditions (8-9) based on the local similarity and local non-similarity methods (Minkowycz and Sparrow [30]). For the first level of truncation the $\varepsilon$ derivatives in equations (11-12) can be neglected. The governing equations for the first level of the truncation are:

$\left(n f^{\prime^{n-1}}+2 G r^{*} e^{\gamma \theta} f^{\prime}\right) f^{\prime \prime}=e^{\gamma \theta} \theta^{\prime}+\gamma \theta^{\prime} f^{\prime n}$

$\theta^{\prime \prime}+\frac{1}{2} f \theta^{\prime}+\varepsilon f^{\prime} \theta+\frac{4}{3} R\left(\left(\left(C_{T}+\theta\right)^{3} \theta^{\prime}\right)^{\prime}\right)=0$

The corresponding boundary conditions are

$\eta=0: f(\varepsilon, \eta)=0, \theta(\varepsilon, \eta)=1$

$\eta \rightarrow \infty: f^{\prime}(\varepsilon, \eta) \rightarrow 0, \theta(\varepsilon, \eta) \rightarrow 0$

For the second level of truncation, we introduce two auxiliary variables $G=\frac{\partial f}{\partial \varepsilon}, H=\frac{\partial \theta}{\partial \varepsilon}$ and restore all of neglected terms at the first level of truncation.

Thus, the governing equations at the second level are:

$\left(n f^{\prime^{n-1}}+2 G r * e^{\gamma \theta} f^{\prime}\right) f^{\prime \prime}=e^{\gamma \theta} \theta^{\prime}+\gamma \theta^{\prime} f^{\prime n}$

$\theta^{\prime \prime}+\frac{1}{2} f \theta^{\prime}+\varepsilon f^{\prime} \theta+\frac{4}{3} R\left(\left(\left(C_{T}+\theta\right)^{3} \theta^{\prime}\right)^{\prime}\right)=\varepsilon\left(f^{\prime} H-\theta^{\prime} G\right)$

The corresponding boundary conditions are

$$
\begin{aligned}
& \eta=0: f(\varepsilon, \eta)+2 \varepsilon \frac{\partial f(\varepsilon, \eta)}{\partial \varepsilon}=0, \theta(\varepsilon, \eta)=1 \\
& \eta \rightarrow \infty: f^{\prime}(\varepsilon, \eta) \rightarrow 0, \theta(\varepsilon, \eta) \rightarrow 0
\end{aligned}
$$

The introduction of the two new dependent variables $G$ and $H$ in the problem requires two additional equations with appropriate boundary conditions. These can be obtained by differentiating the equations (16) and (17) with respect to $\varepsilon$ and neglecting the terms $\frac{\partial G}{\partial \varepsilon}$ and $\frac{\partial H}{\partial \varepsilon}$.

This generates two auxiliary equations:

$$
\begin{aligned}
& \left(n f^{\prime n-1}+2 G r^{*} e^{\gamma \theta} f^{\prime}\right) G^{\prime \prime}+\left(n(n-1) f^{\prime n-2}\right. \\
& \left.G^{\prime}+2 G r^{*} e^{\gamma \theta} G^{\prime}+2 \gamma G r^{*} e^{\gamma \theta} H f^{\prime}\right) f^{\prime \prime}=e^{\gamma \theta} \\
& \left(H^{\prime}+\gamma H \theta^{\prime}\right)+\gamma f^{\prime n-1}\left(n \theta^{\prime} G^{\prime}+f^{\prime} H^{\prime}\right)
\end{aligned}
$$

$$
\begin{aligned}
& H^{\prime \prime}\left(1+\frac{4}{3} R\left(C_{T}+\theta\right)^{3}\right)+f^{\prime} \theta-f^{\prime} H+\frac{1}{2} f \\
& H^{\prime}+\frac{3}{2} G \theta^{\prime}+8 R\left(C_{T}+\theta\right) H \theta^{\prime 2}+4 R\left(C_{T}+\theta\right)^{2} \\
& \left(H \theta^{\prime \prime}+2 H^{\prime} \theta^{\prime}\right)=\varepsilon\left(G^{\prime} H-H^{\prime} G-G^{\prime} \theta-f^{\prime} H\right)
\end{aligned}
$$

The corresponding boundary conditions are

$$
\begin{aligned}
& \eta=0: G(\varepsilon, \eta)=0, H(\varepsilon, \eta)=0 \\
& \eta \rightarrow \infty: G^{\prime}(\varepsilon, \eta) \rightarrow 0, H(\varepsilon, \eta) \rightarrow 0
\end{aligned}
$$

\section{RESULTS AND DISCUSSION}

The coupled non-linear differential equations (18), (19), (22) and (23) along with the boundary conditions (20), (21), (24) and (25) are solved using forth order Runge-Kutta method with a shooting technique. The integration length $\eta_{\infty}$ varies with the parameter values and it has been suitably chosen each time such that the boundary conditions at the outer edge of the boundary layer are satisfied. In order to assess the accuracy of the solution, the present results for the heat transfer coefficients are compared with those obtained by Murthy and Singh [15] in case of Newtonian fluid of constant viscosity in absence of dispersion and the comparison is given in Table 1, which indicates that the present numerical results are in good agreement. The following values are considered for the parameters: $0.5 \leq n \leq 1.5,0 \leq \gamma \leq 0.5$, $0 \leq R \leq 1,0.01 \leq \varepsilon \leq 0.1$ and $0.01 \leq G r^{*} \leq 1.0$. The variation velocity, temperature and heat transfer coefficient (given by equation (13)) are shown for some selected values of the parameters through figures.

Non-dimensional velocity in the non-Darcy medium is plotted for fixed value of $G r^{*}, \gamma$ and $R$ for various values of power law index $n$ and viscous dissipation parameter $\varepsilon$ in Fig. (2). It is interesting to note that the value of the slip velocity $f^{\prime}$ increases with the power law index $n$. And at the same time, an increase in the value of the dissipation parameter increases the velocity distribution inside the boundary layer. In Figs. (3a and 3b). the non-dimensional velocity profiles are plotted in the non-Darcy medium for $n=0.5$ (pseudoplastic fluid) and $n=1.5$ (dilatant fluid), respectively with fixed value of $G r^{*}$ and $\varepsilon$ for various values of $\gamma$ and $R$. It is observed that for all $n(n<1, n=1$ and $n>1)$ the velocity increases inside the boundary layer as the viscosity parameter increases and, therefore, decreases the boundary layer thickness, which results in decrease in temperature as

Table 1. Comparison of the Heat Transfer Coefficient $-\theta^{\prime}(0)$ for Newtonian Fluid when $R=\gamma=0$

\begin{tabular}{|c|c|c|}
\hline$G r^{*}=G=1$ & Murthy and Singh (Series solution) & Present results (LNS method) \\
\hline \hline$\varepsilon=0.0$ & 0.3658 & 0.3658 \\
\hline$\varepsilon=0.01$ & 0.3619 & 0.3619 \\
\hline$\varepsilon=0.1$ & 0.3261 & 0.3262 \\
\hline
\end{tabular}




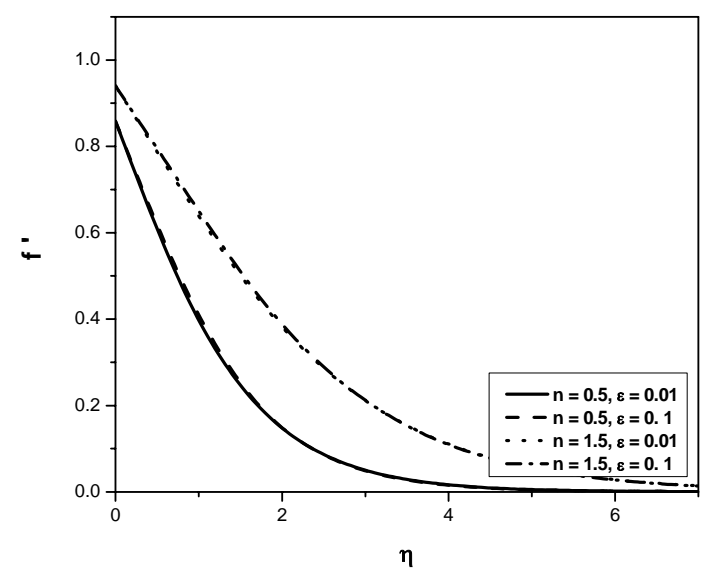

Fig. (2). Variation of velocity distribution with $\eta$ varying $n$ and $\varepsilon$ fixing $G r^{*}=0.01, \gamma=0.0$ and $R=0.0$.
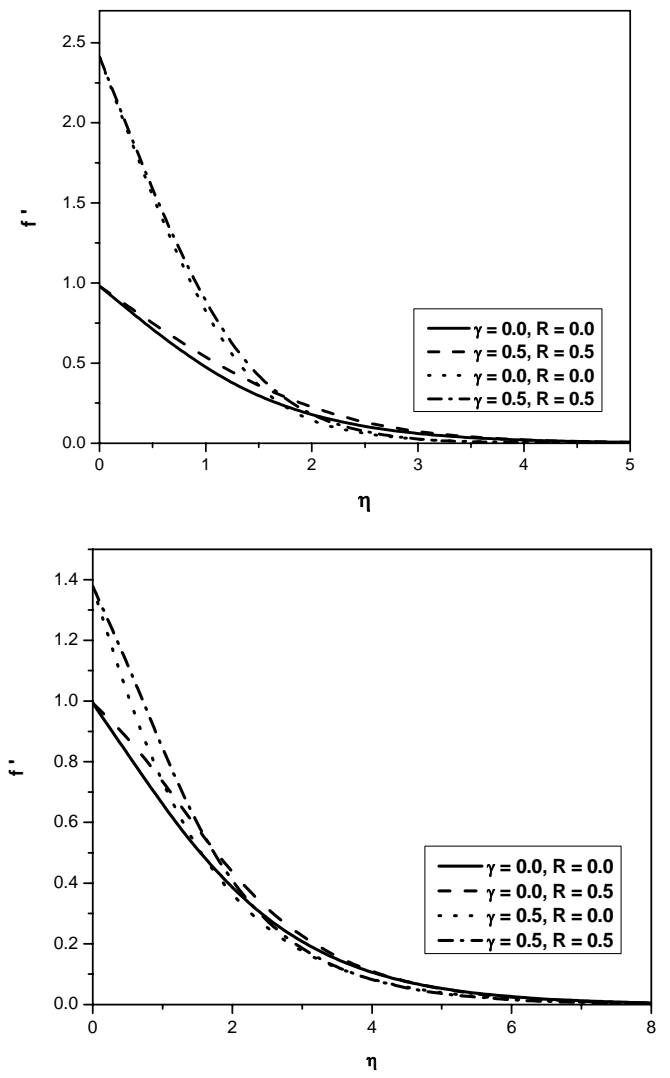

Fig. (3). (a) Variation of velocity distribution with $\eta$ for $n=0.5$ varying $\gamma$ and $R$ fixing $G r^{*}=0.01$ and $\varepsilon=0.01$. (3b). Variation of velocity distribution with $\eta$ for $n=1.5$ varying $\gamma$ and $R$ fixing $G r^{*}=0.01$ and $\varepsilon=0.01$.

indicate in the Figs. (5a and 5b). Also a raise in the value of the radiation parameter results in a rise in the velocity distribution inside the boundary layer for all vales of the power law index $n$.

The variation of non-dimensional temperature distribution $\theta$ with the similarity variable $\eta$ for two different values of $n$ and $\varepsilon$ is plotted in Fig. (4). The temperature profile rises with increasing values of the dissipation parameter for all $n$. In other hand the thickness of the temperature boundary layer decreases with increasing the power law index $n$ which results in an increase in the heat transfer coefficient with increasing the power law index $n$ as indicated in the Figs. (6-9). Figs. (5a and 5b), respectively, show the variation of the non-dimensional temperature profile $\theta$ across the boundary layer for $n=0.5$ and $n=1.5$ various values of viscosity parameter $\gamma$ and $R$ for fixed values of other parameters. It is seen that increasing the viscosity parameter $\gamma$ tends to decreases the thermal boundary layer thickness results increment in heat transfer coefficient as shown in the Figs. (6 and 9). Again with an increase in the coefficient of thermal radiation $R$, a rise in temperature distribution in the boundary layer is seen for all values of $n$.

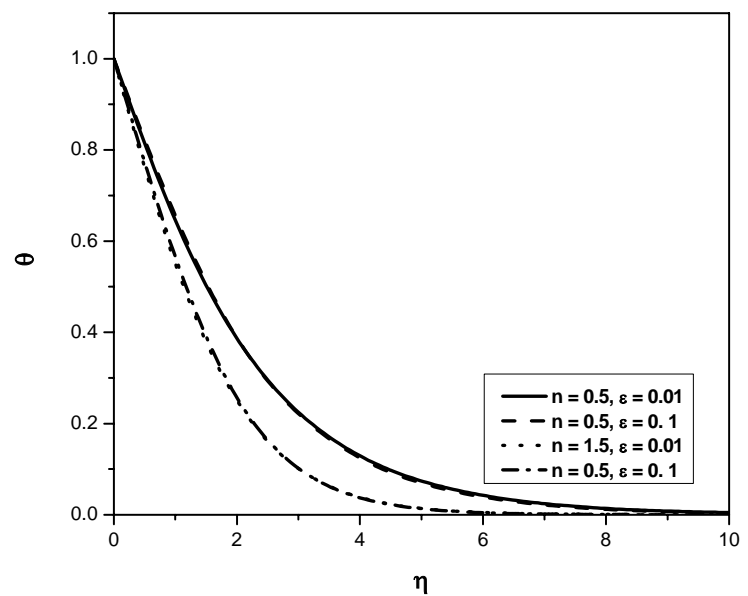

Fig. (4). Variation of temperature distribution with $\eta$ varying $n$ and $\varepsilon$ fixing $G r^{*}=0.01, \gamma=0.0$ and $R=0.0$.
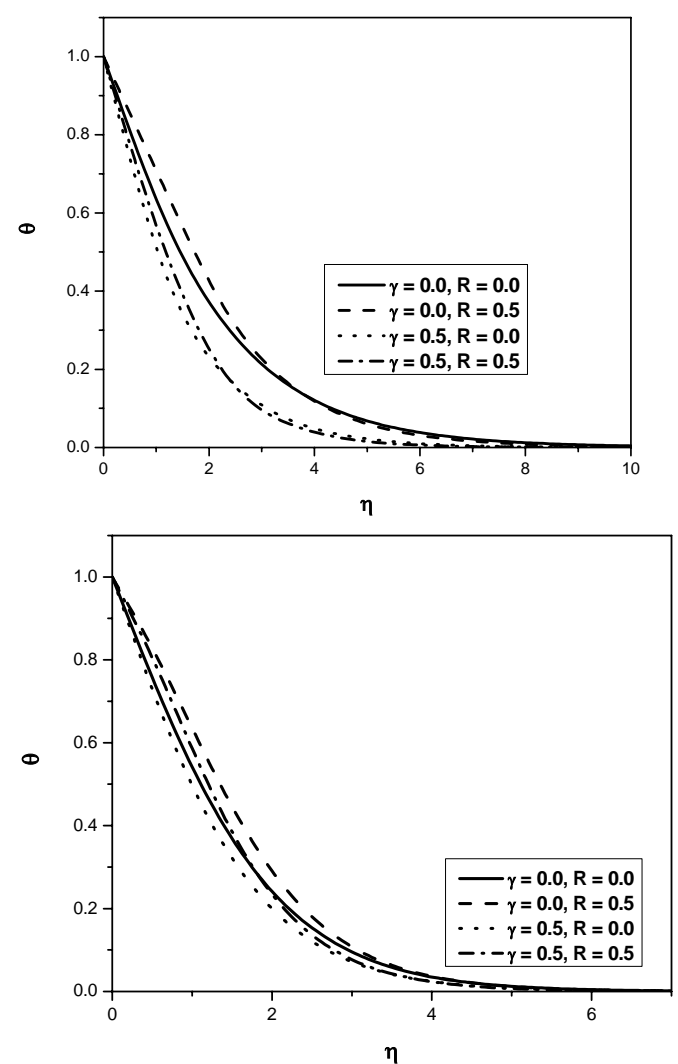

Fig. (5). (a) Variation of temperature distribution with $\eta$ for $n=0.5$ varying $\gamma$ and $R$ fixing $G r^{*}=0.01$ and $\varepsilon=0.01$. (5b). Variation of temperature distribution with $\eta$ for $n=1.5$ varying $\gamma$ and $R$ fixing $G r^{*}=0.01$ and $\varepsilon=0.01$. 
Fig. (6) illustrates the variation of the Nusselt number against $n$ for different values of $\gamma$ and $\varepsilon$, with fixed value of other parameters. It is observed that the heat transfer coefficient increases with increasing power law index $n$ and viscosity parameter $\gamma$. Similar behavior was observed by Jayanthi and Kumari [24], considering viscosity of liquid varies inversely as a linear function of temperature. On the other hand heat transfer coefficient decreases with increasing the dissipation parameter $\varepsilon$ for all values of $n$. It is also pointed out by Murthy and Singh [15] while studying viscous dissipation of natural convection for Newtonian fluid. The rise in the heat transfer coefficient due to the presence of $\gamma$ is more pronounced for the pseudoplastic fluids while the fall in the heat transfer coefficient due to increasing $\varepsilon$ is more for the dilatant fluids. In Fig. (7) the variation of heat transfer coefficient as a function of the power law index $n$ is plotted for different values of $G r^{*}$ and $\varepsilon$ with fixed values of other parameters. The heat transfer coefficient decreases with increasing $G r^{*}$ and $\varepsilon$ for all $n$. The influence of nonDarcy parameter is more important for dilatant fluids. It is also noted that the effect dissipation on heat transfer coefficient is diminishing with increasing non-Darcy effect for all values of $n$, more significantly if the porous media is saturating with dilatant fluids.

The variation of non-dimensional heat transfer coefficient with the power law index $n$ for two different values of $\varepsilon$ and $R$ is plotted in Fig. (8). It is noted that for the dilatant

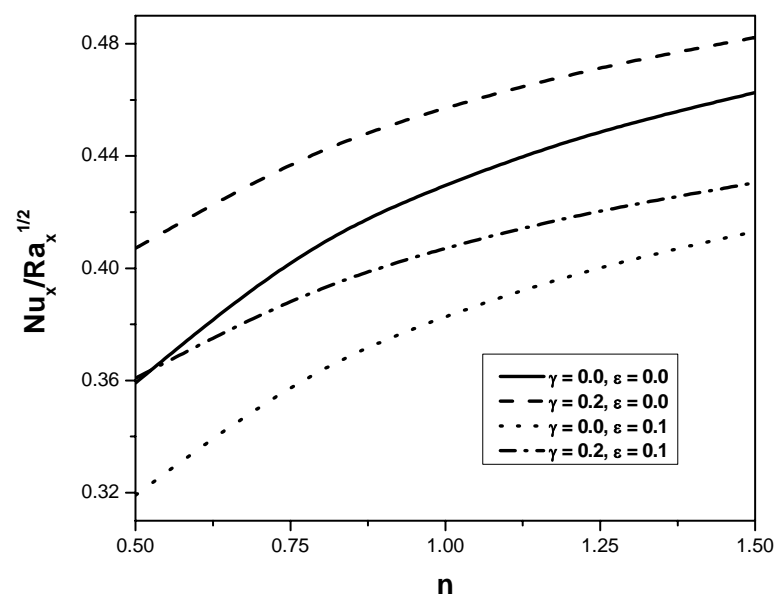

Fig. (6). Variation of Nusselt number with $n$ varying $\gamma$ and $\varepsilon$ fixing $G r^{*}=0.1$ and $R=0$.

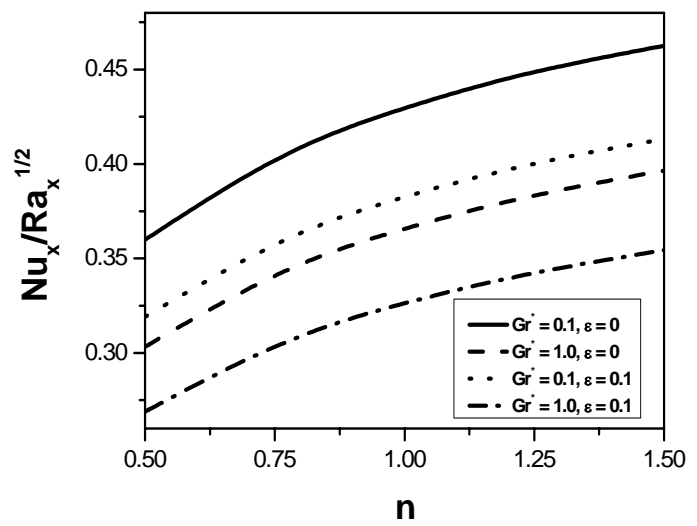

Fig. (7). Variation of Nusselt number with $n$ varying $G r^{*}$ and $\varepsilon$ fixing $\gamma=0.0$ and $R=0$. fluid saturated porous media, thermal radiation has more significant effect along with the viscous dissipation parameter on the heat transfer coefficient. In Fig. (9) variation of the Nusselt number as a function of power law index $n$ is shown for two different values of $\gamma$ and $R$ with fixed value of $G r^{*}$ and $\varepsilon$. From this figure, a raise in the Nusselt number is evident with increasing values of $n, \gamma$ and the thermal radiation $R$. Also an important observation is that the raise in the heat transfer coefficient due to increase in the viscosity parameter is more significant when considered along with thermal radiation.

\section{CONCLUSIONS}

In this study the problem of combined effect of viscous dissipation and radiation on natural convection heat transfer from vertical flat plate in a non-Newtonian fluid saturated non-Darcy porous medium with variable viscosity is analyzed. It is noted that the velocity and temperature profiles as well as the heat transfer coefficient are significantly affected by the viscous dissipation, radiation of the medium and viscosity of fluid. It is seen that the heat transfer coefficient increases with increasing in the power law index $n$ and viscosity parameter $\gamma$ while it decreases with the dissipation parameter $\varepsilon$. The rise in the heat transfer coefficient due to the effect of $\gamma$ is more pronounced for the pseudoplastic $(n<1)$ fluids and especially in company with thermal radiation while the fall in the heat transfer coefficient due to increases $\varepsilon$ is more when the porous media saturated with

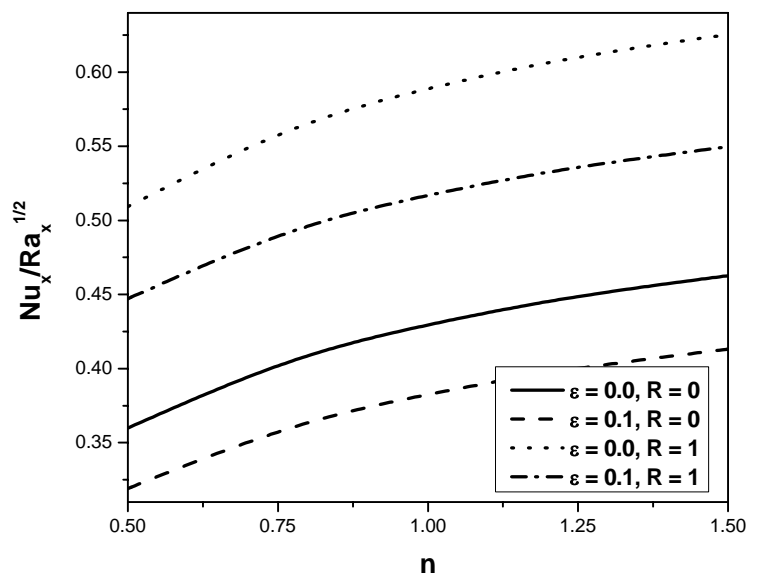

Fig. (8). Variation of Nusselt number with $n$ varying $R$ and $\varepsilon$ fixing $G r^{*}=0.1$ and $\gamma=0$.

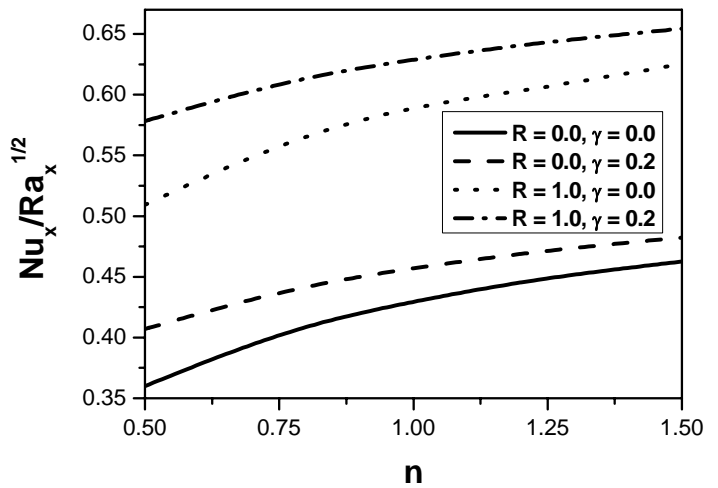

Fig. (9). Variation of Nusselt number with $n$ varying $R$ and $\gamma$ fixing $G r^{*}=0.1$ and $\varepsilon=0$. 
dilatant ( $n>1$ ) fluids. Finally, the presence of thermal radiation influences the effect of viscous dissipation parameter on the heat transfer coefficient for any fluids (Newtonian or non-Newtonian fluid) and more affective when the porous media is saturated with dilatant fluids.

\section{NOMENCLATURE}

\begin{tabular}{|c|c|c|}
\hline$b$ & $=$ & Coefficient in the Forchheimer term \\
\hline$c$ & $=$ & Forchheimer coefficient \\
\hline$c_{p}$ & $=$ & Specific heat at constant pressure $[\mathrm{J} / \mathrm{kg} \mathrm{K}]$ \\
\hline$C_{T}$ & $=$ & Temperature ratio \\
\hline$d$ & $=$ & Pore diameter $[\mathrm{m}]$ \\
\hline$f$ & $=$ & Dimensionless stream function \\
\hline$g$ & $=$ & Acceleration due to gravity $\left[\mathrm{m} / \mathrm{s}^{2}\right]$ \\
\hline$G r *$ & $=$ & $\begin{array}{l}\text { Inertia Parameter based on permeability for } \\
\text { power law fluid }\end{array}$ \\
\hline$k *$ & $=$ & Mean absorption coefficient \\
\hline$K^{*}$ & $=$ & $\begin{array}{l}\text { Intrinsic permeability of the porous me- } \\
\text { dium for flow of power law fluid }\left[\mathrm{m}^{2}\right]\end{array}$ \\
\hline$K$ & $=$ & Permeability of the porous medium $\left[\mathrm{m}^{2}\right]$ \\
\hline$n$ & $=$ & Power law index \\
\hline$N u$ & $=$ & Nusselt number \\
\hline$q_{y}^{r}$ & $=$ & Radiative heat flux $\left[\mathrm{J} /\left(\mathrm{m}^{2} \mathrm{~s}\right)\right]$ \\
\hline$R$ & $=$ & Radiation parameter \\
\hline$R a_{x}$ & $=$ & Local Rayleigh number \\
\hline$T$ & $=$ & Temperature [ K ] \\
\hline$u, v$ & $=$ & $\begin{array}{l}\text { Average velocity components in } \mathrm{x} \text { and } \mathrm{y} \\
\text { directions }[\mathrm{m} / \mathrm{s}]\end{array}$ \\
\hline$x, y$ & $=$ & $\begin{array}{l}\text { Coordinates along and perpendicular to the } \\
\text { wall }[\mathrm{m}]\end{array}$ \\
\hline
\end{tabular}

\section{Greek Symbols}

$\begin{array}{lll}\alpha & = & \text { Thermal diffusivity }\left[\mathrm{m}^{2} / \mathrm{s}\right] \\ \beta_{T} & = & \text { Coefficient of thermal expansion }[1 / \mathrm{K}] \\ \varepsilon & = & \text { Dissipation parameter } \\ \phi & = & \text { Porosity of the saturated porous medium } \\ \gamma & = & \text { Viscosity parameter } \\ \eta & = & \text { Similarity variable } \\ \mu & = & \text { Fluid consistency of the inelastic non- } \\ \theta & = & \text { Dewtonian power-law fluid }[\mathrm{kg} /(\mathrm{ms})] \\ & & \end{array}$
$\rho \quad=\quad$ Density $\left[\mathrm{kg} / \mathrm{m}^{3}\right]$
$\sigma \quad=\quad$ Stefan-Boltzman constant
$\psi \quad=\quad$ Dimensionless stream function
$\boldsymbol{\theta}_{w}=T_{w}-T_{\infty}$

\section{Subscripts}

$\begin{array}{lll}w & = & \text { Condition at the wall } \\ \infty & = & \text { Condition at the ambient medium }\end{array}$

\section{ACKNOWLEDGEMENTS}

The authors would like to acknowledge sincerely the financial assistance received from the CSIR, India through the research project grant numbers respectively, 09/081(0596)/ 2006-EMR-1 and 25(155)/07/EMR-II. The work was partly supported by the Research Grants Council of the Hong Kong Special Administrative Region, China, through Project No. HKU 715609E.

\section{REFERENCES}

[1] A.V. Shenoy, "Non-Newtonian fluid heat transfer in porous media", Advances in Heat Transfer, New York : Academic Press, 1994, vol. 24, pp. 101-190.

[2] H. T. Chen and C. K. Chen, "Natural convection of a nonNewtonian fluid about a horizontal cylinder and sphere in a porous medium”, International Communications in Heat and Mass Transfer, vol.15, pp. 605-614, 1988 .

[3] H. T. Chen and C. K. Chen, "Natural convection of non-Newtonian fluids along a vertical plate embedded in a porous medium", $A S M E$ Journal of Heat Transfer, vol. 110, pp. 257-260, 1988.

[4] A. Nakayama and H. Koyama, "Buoyancy induced flow of nonNewtonian fluids over a non-isothermal body of arbitrary shape in a fluid-saturated porous medium", Applied Scientific Research, vol. 48, pp. 55-70, 1991.

[5] K. N. Mehta and K. N. Rao, "Buoyancy-induced flow of nonNewtonian fluids over a non-isothermal horizontal plate embedded in a porous medium", International Journal of Engineering Science, vol. 32, pp. 521-525, 1994.

[6] K. N. Mehta and K. N. Rao, "Buoyancy-induced flow of nonNewtonian fluids in a porous medium past a vertical plate with non-uniform surface heat flux", International Journal of Engineering Science, vol. 32, pp. 297-302, 1994.

[7] A. V. Shenoy, "Darcy-Forchheimer natural, forced and mixed convection heat transfer in non-Newtonian power-law fluidsaturated porous media", Transport in Porous Media, vol. 11, pp. 219-241, 1993

[8] B. Gebhart, "Effect of viscous dissipation in natural convection", Journal of Fluid Mechanics, vol. 14, pp. 225-235, 1962.

[9] B. Gebhart and J. Mollendorf, "Viscous dissipation in external natural convection flows", Journal of Fluid Mechanics, vol. 38, pp. 97-107, 1969.

[10] R. M. Fand and J. Brucker, "A correlation for heat transfer by natural convection from horizontal cylinder that accounts for viscous dissipation", International Journal of Heat and Mass Transfer, vol. 26, pp. 709-726, 1983.

[11] R. M. Fand, T. E. Steinberger and P. Cheng, "Natural convection heat transfer from a horizontal cylinder embedded in a porous medium", International Journal of Heat and Mass Transfer, vol. 29, pp. 119-133, 1986.

[12] A. Bejan, Convective Heat Transfer, New York: Wiley, 1984, pp. 343-416.

[13] A. Nakayama and I. Pop, "Free convection over a non-isothermal body in a porous medium with viscous dissipation fiber beds", International Communications in Heat and Mass Transfer, vol. 16, pp. 173-180, 1989. 
[14] C. L. Tucker III and R. B. Dessenberger, "Governing equations for flow and heat transfer in stationary fiber beds", In Flow and Rheology in Polymer Composits Manufacturing, S. G. Advani, Ed. Amsterdam: Elsevier Science, 1994.

[15] P. V. S. N. Murthy and P. Singh, "Effect of viscous dissipation on a non-Darcy natural convection regime", International Journal of Heat and Mass Transfer, vol. 40, pp. 1251-1260, 1997.

[16] M. F. El-Amin, M. A. El-Hakiem and M. A. Mansour, "Effect of viscous dissipation on a power-law fluid over plate embedded in a porous medium", Heat and Mass Transfer, vol. 39, pp. 807-813, 2003.

[17] A. Raptis, "Radiation and free convection flow through a porous medium", International Communications in Heat and Mass Transfer, vol. 25, pp. 289-295, 1998.

[18] A. J. Chamkha, "Solar radiation assisted convection in uniform porous medium supported by a vertical plate", Transaction ASME Journal of Heat Transfer, vol. 119, pp. 89-96, 1997.

[19] P. V. S. N. Murthy, S. Mukherjee, D. Srinivasacharya and P. V. S. S. S. R. Krishna, "Combined radiation and mixed convection from a vertical wall with suction/injection in a non-Darcy porous media", Acta Mechanica, vol. 168, pp. 145-156, 2004.

[20] A. A. Mohammadein and M. F. El-Amin, "Thermal radiation effect on power law fluid over a Horizontal plate embedded in a porous medium", International Communications in Heat and Mass Transfer, vol. 27, pp. 1025-1035, 2000.

[21] F. C. Lai and F. A. Kulacki, "The effect of variable viscosity on convection heat transfer along a vertical surface in a saturated porous medium", International Journal of Heat and Mass Transfer, vol. 33, pp. 1028-1031, 1990.

[22] J. X. Ling and A. Dybbs, "The effect of variable viscosity on forced convection over a flat plate submersed in a porous medium",
Transaction ASME Journal of Heat Transfer, vol. 114, pp. 10631065,1992 .

[23] A. Postelnicu, T. Gorsan and I. Pop, "The effect of variable viscosity on forced convection flow past a horizontal flat plate in a porous medium with internal heat generation", Mechanics Research Communications, vol. 28, pp. 331-337, 2001.

[24] S. Jayanthi and M. Kumari, "Effect of variable viscosity on nonDarcy free or mixed convection flow on a vertical surface in a nonNewtonian fluid saturated porous medium", Applied Mathematics and Computation, vol. 186, pp. 1643-1659, 2007.

[25] E. M. A. Elbashbeshy, "Free convection flow with variable viscosity and thermal diffusivity along a vertical plate in the presence of the magnetic field", International Journal of Engineering Science, vol. 38, pp. 207-213, 2000.

[26] M. Massoudi and T. X. Phuoc, 'Flow of a generalized second grade non-Newtonian fluid with variable viscosity", Continuum Mechanics Thermodynamics, vol. 16, pp. 529-538, 2004.

[27] M. A. Seddeek, A. A. Darwish and M. S. Abdelmeguid, "Effect of chemical reaction and variable viscosity on hydromagnetic mixed convection heat and mass transfer for Hiemenz flow through porous media with radiation", Communications in Nonlinear Science and Numerical Simulation, vol. 12, pp. 195-213, 2007.

[28] R. H. Christopher and S. Middleman, "Power law fluid flow through a packed tube", Ind. Eng. Chem. Fundamentals, vol. 4, pp. 422-426, 1965.

[29] R. V. Dharmadhikari and D. D. Kale, "The flow of non-Newtonian fluids through porous media", Chemical Engineering Science, vol. 40, pp. 527-529, 1985.

[30] W. J. Minkowycz and E. M. Sparrow, "Local non-similar solution for natural convection on a vertical cylinder", Journal of Heat Transfer, vol. 96, pp. 178-183, 1974. 